\title{
Constitutional Symptom
}

National Cancer Institute

\section{Source}

National Cancer Institute. Constitutional Symptom. NCI Thesaurus. Code C38469.

A group of symptoms that affect an individual's general well being. Representative examples include fever, chills, fatigue, weakness, and weight loss. 